\title{
Miniplates with A New Design As Skeletal Anchorage for Intrusion of Posterior Maxillary Segment During Correction of Skeletal Anterior Open Bite (A Cohort Clinical Study)
}

\author{
Original \\ Article \\ Maha M. Mohamed ${ }^{a}$, Hatem H. Alahmady ${ }^{b}$ Ahmad Abedalazim ${ }^{c}$ and \\ Mohsena A. Abderazik ${ }^{a}$ \\ ${ }^{a}$ Department of Orthodontics, ${ }^{b}$ Department of Oral and Maxillofacial Surgery, \\ Faculty of Dentistry, Al-Azhar University, 'Department of Oro-dental Genetics, \\ Human genetics division national research Center, Cairo, Egypt
}

\begin{abstract}
Objective: This study aimed to evaluate the effect of newly designed miniplates that used as skeletal anchorage for maxillary molars' intrusion during correction of skeletal anterior open bite (SAOB).

Subjects and Methods: A sample of 22 patients with an age range from 14 to 22 years, suffering from skeletal anterior open bite (SAOB) with increased posterior maxillary vertical height. A new designed custom-made miniplates used after adaptation on 3D model of maxilla for every patient. They were used as buccal skeletal anchorage for maxillary molars' intrusion. The measurements, including maxillary dento-alveolar heights $(\mathrm{mm})$, buccal crestal alveolar bone heights ( $\mathrm{mm}$ ), bucco-palatal angulations (B-P $\square$ ) of right and left maxillary first permanent molars, 3 months after intrusion commencement.

Results: The dento-alveolar height as well as the buccal crestal alveolar height decreased significantly $(p \leq 0.001$ and $p \leq 0.05$, respectively) after intrusion. Similarly, the B-P angulations increased significantly $(p \leq 0.01)$ after intrusion.

Conclusion: New custom-made preadapted miniplates' designs were effective for posterior maxillary molar intrusion in cases of SAOB. Both the posterior maxillary dento-alveolar and buccal crestal alveolar bone heights diminished significantly.
\end{abstract}

Key Words: Intrusion, Skeletal anterior open bite and Miniplates.

Received: 12 March 2020, Accepted: 18 April 2020.

Corresponding Author: Maha M. Mohamed, Department of Orthodontics, Faculty of Dentistry, Al-Azhar University, XXX, Egypt, Mobile: +2 01145063342, E-mail: mahaorthodontist2014@gmail.com.

ISSN: 2090-097X, July 2019, Vol. 10, No. 3

\section{INTRODUCTION}

Skeletal anterior open bite is one of the most difficult cases in orthodontics not only to treat, but also to retain due to its multifactorial nature. In adult patients, treatment of severe skeletal anterior open bite consists mainly of surgically repositioning both maxilla and mandible. This is true regarding the adult because they have little growth potential and open bites are often combined with a long face tendency ${ }^{[1-3]}$. Many treatment modalities proposed for such cases, such as high pull head gear, vertical pull chin cup, intraoral functional appliances like Harvold activator, open bite bionator, posterior bite blocks, as intrusive modalities whereby successful molar intrusion was achieved in an attempt to correct SOB. Unfortunately, these techniques have a number of other demerits ${ }^{[4-9]}$. Noteworthy, surgical treatment of SOB malocclusion by conventional Le Fort 1 surgery was considered as the typical treatment or the first option for SAOB malocclusion ${ }^{[10]}$. Unfortunately, patient acceptance for this treatment modality was almost negative and not accepted by most of the current research patients. The second treatment option was intrusion of the posterior teeth to correct the anterior open bite. Therefore, molar intrusion considered to be the best treatment choice because it leads to an autorotation of the mandible in the counterclockwise direction, thus improving the long anterior facial height ${ }^{[11,12]}$. However, there might be other, less-invasive treatment options not requiring orthognathic surgery. If it is possible to orthodontically intrude posterior teeth, the accompanying changes in occlusal plane, mandibular plane, lower anterior face height, and anterior dental overbite would close the patient's open bite.

However, intrusion of posterior or anterior dentition is always difficult to achieve without extrusion of the anchorage teeth as a side effect ${ }^{[10-17]}$. The TADs, such as dental implants ${ }^{[14,18-20]}$ miniplates $^{[15,21-25]}$ and miniscrews ${ }^{[16,23,26-28]}$ have been developed in a trial to provide the solution for the extrusion of anchorage teeth problem. Based on the mentioned reports, the present study aimed to treat SAOB malocclusion by posterior maxillary intrusion via two designs of buccal miniplates and palatal miniscrews $^{[13,21,22,29-31]}$. Cone beam computed tomography (CBCT) was used for evaluation of the intrusion due to the proposed limitations of the two dimensional radiographic assessments $^{[29-31]}$.

\section{SUBJECTS AND METHODS}

The present clinical study was conducted initially on 22 patients with age range ${ }^{[14-22]}$ years old with skeletal anterior open bite due to increased posterior maxillary dentoalveolar height. All patients had a full set of permanent 
dentition not including the third molar. All participants had negative history of serious systemic illness, blood diseases, bleeding disorders and bone diseases. The patients and/or guardians were fully informed about the procedures, and informed written consents were obtained before commencing the study and approved by the Ethical Committee of Faculty of Dental Medicine for Girls, AlAzhar University, Cairo, Egypt.

The following routine orthodontic records were obtained for each patient before treatment:

- Extra-oral photographs (frontal at rest, frontal during smile, right and left profile views).

- Intra-oral photographs (frontal, right and left side views, upper and lower occlusal views).

- Orthodontic study models.

- Cone beam computed tomography CBCT for whole skull.

Segmental fixed orthodontic appliance* was used in the posterior maxillary segment including molars and premolars teeth to be aligned. Sequential orthodontic arch wires were used starting from 0.012 " Ni-Ti up to $0.017 \times 0.025$ ” St.St. arch wire (Figure 1).

A newly designed custom made miniplates were used and mounted to a 3D model of maxilla for every patient.
Zygomatic buttresses is bilaterally printed out and used for mounting of skeletal anchorage miniplates buccally in a trial to direct the intrusive force vertically with anterior and posterior components starting from the first maxillary premolar anteriorly to the second maxillary molar posteriorly. While, miniscrews were used for the same purpose palatally.

Cone beam computed tomography (CBCT) for the maxilla was obtained before starting the procedure used as a pretreatment record and for construction of 3D model of maxilla. The DICOM (Digital Imaging and Communication in Medicine) file format imported into Materlialize software (Mimics 10.01, Materlialize, Belgium). Then, after segmentation was done, the maxilla separated from the skull to the level of orbital floor. The right and left maxillary segments had been splited. After virtual planning was completed, the CBCT dataset was converted from the initial DICOM format to a Stereolithography (STL) format to input the CBCT dataset into a 3-D printer and create a stereo-lithographic working model of the maxilla. These models in turn, used for pre-operative bending of the miniplates to be adapted on the corresponding area of the maxilla. It was contoured and bent to conform the shape of the zygomatic bone using miniplates' benders. Finally, the miniplate underwent sterilization procedures to be ready for intraoperative use (Figure $2 \mathrm{a}$ and $\mathrm{b}$ ).
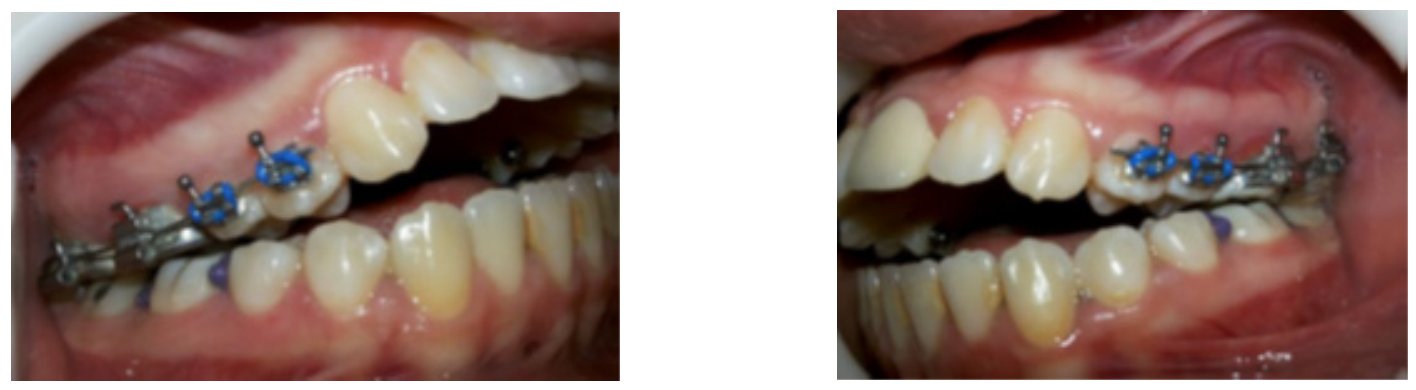

Figure 1: Banding and bonding of the maxillary posterior segment, right and left side.

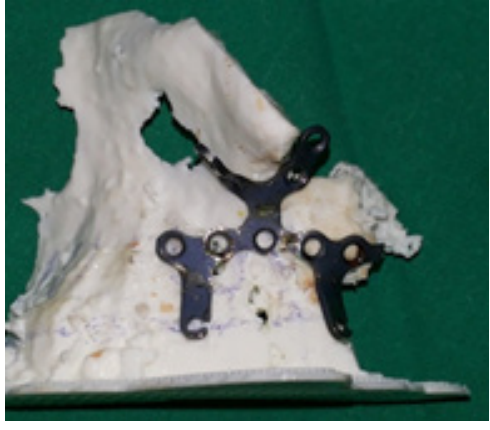

A

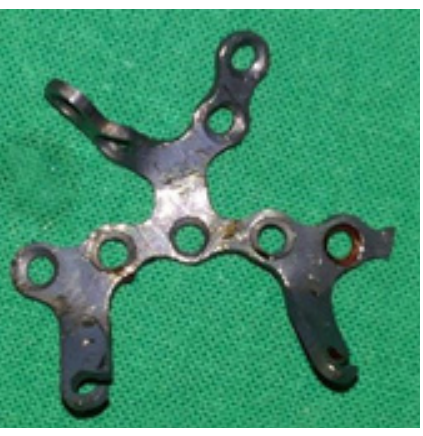

B

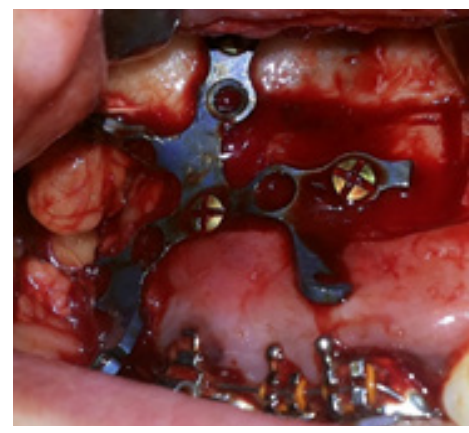

$\mathrm{C}$

Figure 2: Custom-made miniplate A) Adaptation on 3D model for the maxilla, B) The miniplate after bending. C) Intraoral after fixation within the zygomatic buttress. 
The surgical procedures were performed under local anesthesia. Disinfection of the maxillary buccal sulcus and alveolar mucosa with Betadine solution. A horizontal a $2.5 \mathrm{~cm}$ buccal incision was done above the attached gingiva from the first maxillary premolars towards the posterior segment of the maxilla. Full-thickness mucoperiosteal flaps were elevated, taking care not to expose the buccal fat pad. Flap reflection extended vertically to the level of zygomatic buttress. Subsequently, the custom made pre-adapted titanium miniplates were mounted on the zygomatic buttresses bone and the last loop of the miniplate allowed to project through the vestibular wound adjacent to the teeth to be intruded. Five self-tapping screws, $2.3 \mathrm{~mm}$ diameter and $9 \mathrm{~mm}$ length each, were placed to secure the plate to the bone. The mucosal incision was sutured and allowed to heal around the exposed miniplate loops. The procedure took about 15 minutes per plate, and there was minimal patient complications at the time of surgery or postoperatively (Figure $2 \mathrm{c}$ ).

Additionally, palatal mini-screws were used as temporary anchorage device (TAD) to provide palatal intrusive force in both right and left maxillary posterior segment. Vector temporary anchorage system (TAS) miniscrews (1.6 $\mathrm{mm}$ in diameter and $11 \mathrm{~mm}$ in length) made of biocompatible pure titanium were introduced for all patients bilaterally between maxillary second premolar and maxillary first molar in the palatal side using the appropriate screw driver. Disinfection of the implantation site with Betadine solution was done after its determination. Then, few drops of $4 \%$ Articaine hydrochloride local anesthesia with 1200.000/ epinephrine were injected and the pre-determined point of insertion was punched with a periodontal probe to induce a bleeding point. The miniscrew thereafter was mounted onto its screw driver and was self-drilled into the bone (Figure 3).

Buccal and palatal intrusive forces were applied immediately on the posterior maxillary segment using elastic modules for three months with reactivation weekly in an attempt to produce, constant amount of force (150 gm) measured using tension gauge. The force was applied from the miniplate to the upper first and second molar buccal tubes and from the palatal mini-screws to the first and second premolars buttons and the palatal cleats of the first and second molars bands. After completion of the intrusion period, the intruded region was retained by ligating it to the miniplates (Figure 4). Comprehensive fixed orthodontic appliance was used to start leveling and alignments until settling of occlusion (Figure 5).

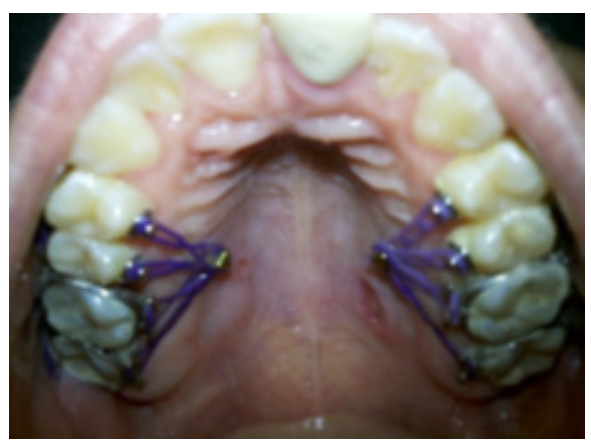

Figure 3: Palatal intrusive mechanics to maxillary premolars and molars using palatal miniscrews.
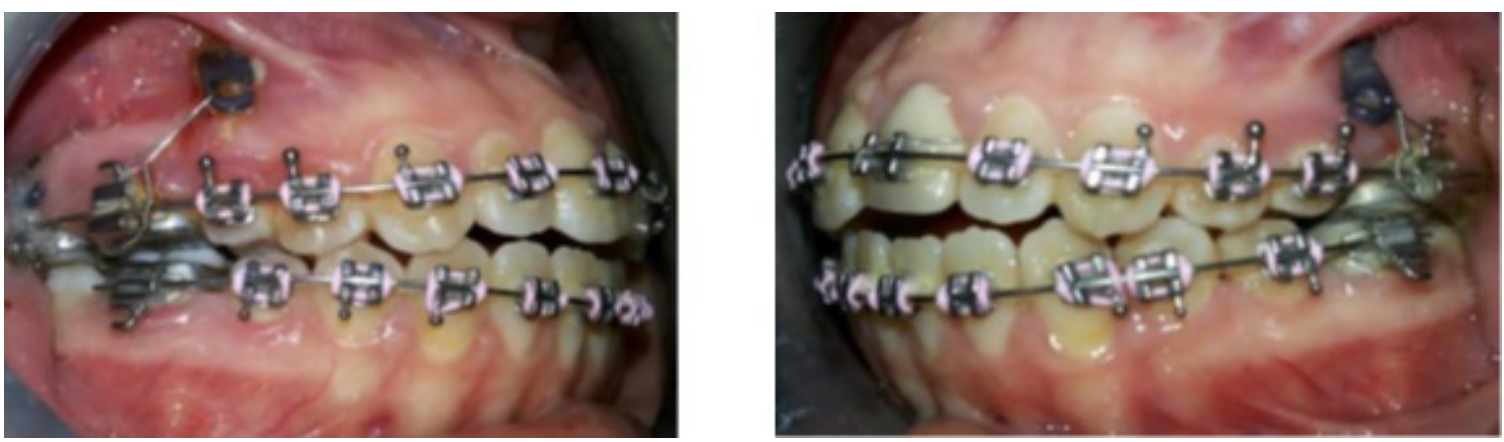

Figure 4: After intrusion completion and commence of comprehensive orthodontic treatment. 

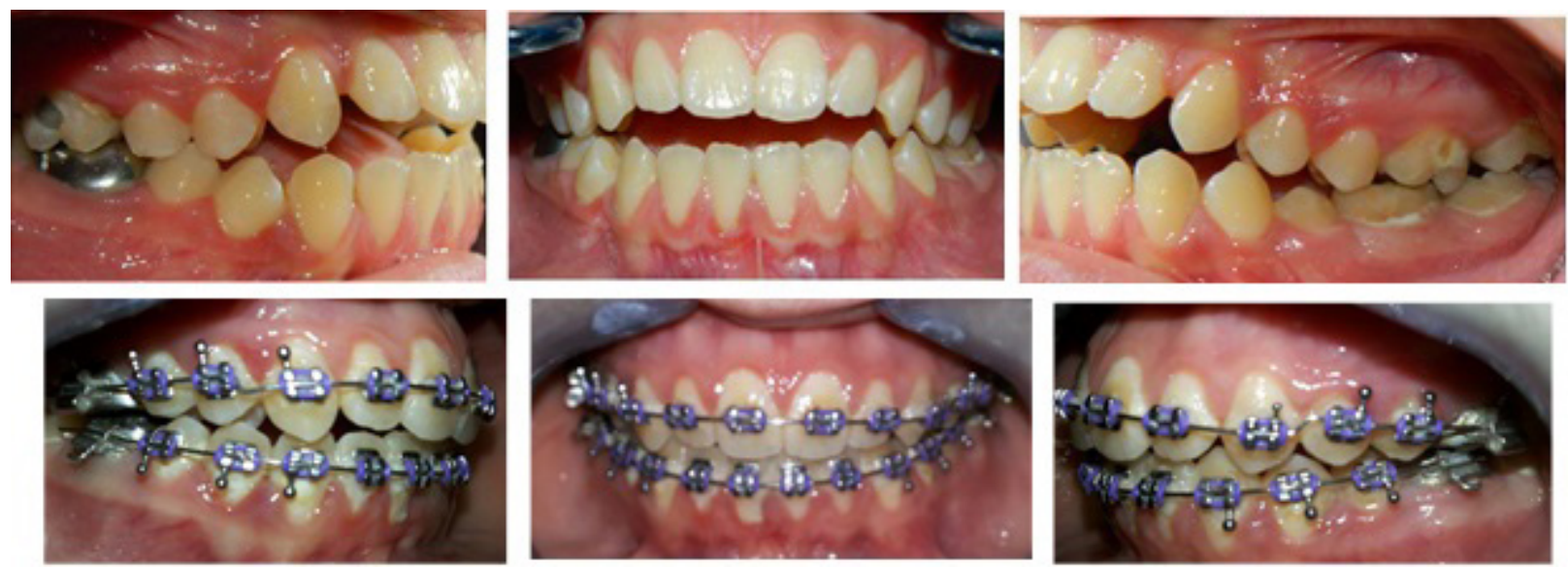

Figure 5: Pretreatment and post intrusion intra-oral photos.

In addition to pre-intrusion $\mathrm{CBCT}$, post-intrusion $\mathrm{CBCT}$ images were obtained too after an average observation period of 3 months. The following CBCT measurements were evaluated before intrusion (T1) and after intrusion (T2):

1. Dento-alveolar height $(\mathrm{mm})$ of right and left maxillary first molars.

2. Bucco-palatal angulation $\left({ }^{0}\right)$ of right and left maxillary first molars.

3. Buccal crestal alveolar bone height $(\mathrm{mm})$ of right and left maxillary first molars.

The collected data were tabulated and statistically analyzed for each variable using Statistical Package for Social Science (SPSS) Version 20. Comparison of the changes in the previous measurements were performed using student's t-test, paired t-test for parametric measures, and Mann-Whitney U test for non-parametric measures.

\section{RESULTS}

The results of the study showed that the dentoalveolar height of right and left first maxillary molars had statistically significant decreases of $1.55(0.71) \mathrm{mm}$ and $1.11(0.71) \mathrm{mm}$, respectively (Figure 6).

On the other hand, the bucco-palatal angulations of first maxillary molars showed significant increases of $1.79(0.74)^{0}$ and $1.89(0.64)^{0}$ in right and left sides, respectively (Figure 7).

Regarding the height of buccal crestal alveolar bone, it was reduced by means of $0.83(0.12) \mathrm{mm}$ and $0.23(0.10)$ $\mathrm{mm}$ in right and left sides, respectively (Figure 8).

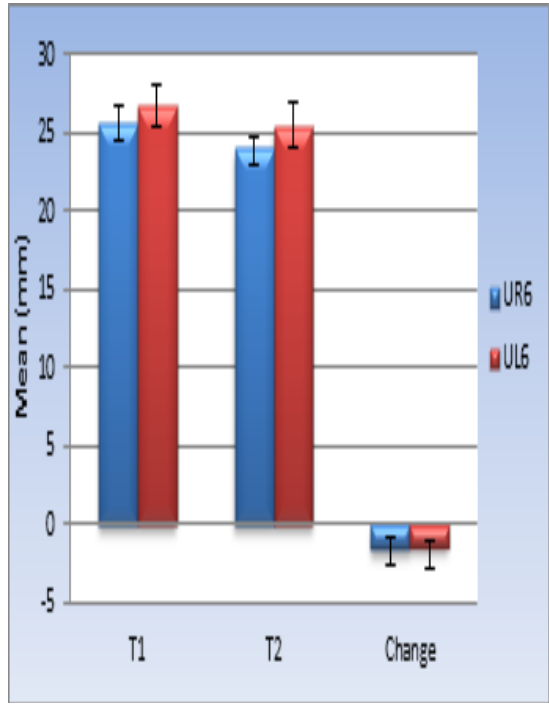

Figure 6: Bar chart representing means of dento-alveolar heights ( $\mathrm{mm}$ ) of UR6 and UL6 before (T1) and after (T2) intrusion.

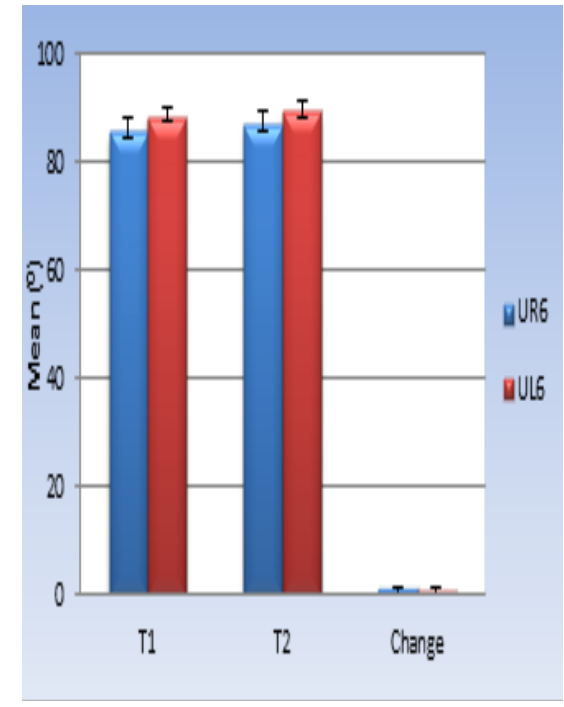

Figure 7: Bar chart representing means of M-D crown angulation of UR6 and UL6 before (T1) and after (T2) intrusion.

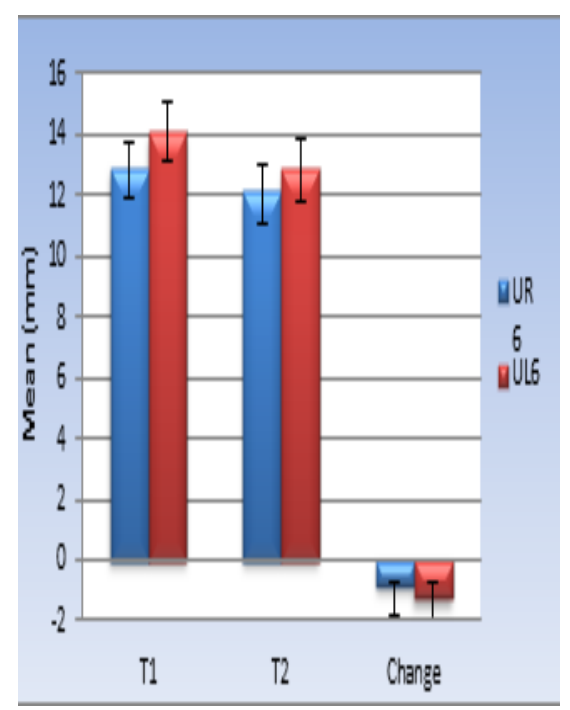

Figure 8: Bar chart representing means of buccal crestal alveolar bone height ( $\mathrm{mm}$ ) of UR6 and UL6 before (T1) and after (T2) intrusion. 


\section{DISCUSSION}

SAOB has been considered one of the most difficult and challenging malocclusions, where combinations of skeletal, dental, and sometimes functional factors interact. Molar intrusion is considered to be the best treatment because it leads to an autorotation (counterclockwise) of the mandible ${ }^{[11,12]}$. However, intrusion of posterior dentition is always difficult to achieve without the side effect of extrusion of the anchorage teeth ${ }^{[12-16]}$. Temporary anchorage devices (TADs) were used to overcome this problem $^{[22-28]}$.

A preoperative CBCT image allows the clinician to evaluate the bone around the insertion site thoroughly in all three dimensions ${ }^{[32]}$. 3D diagnostic imaging has been previously suggested to improve the outcome of implant placement by eliminating distortion errors associated with two-dimensional images and by reducing the risk of injury of adjacent structures ${ }^{[33]}$. Moreover, virtual placement of the mini-plate on the CBCT image, using dedicated software, allows the clinician to precisely determine the final position of the plate during the surgery ${ }^{[32]}$. Several studies have used virtual treatment planning as a means for achieving higher surgical success rates by reducing intra-operative decision-making ${ }^{[32-34]}$. In the current study the duration of surgery was shorter, this was inaccordance to previous study ${ }^{[32]}$. Longer surgeries are associated to larger edemas and more post-operative pain. Pre-operative adaptation of the mini-plates on the model surface is the main advantage of the present method. It allows for maximum contact between the plate and the bony surface during the surgery and therefore significantly reduces the risk for infection and the possibility of miniplate failure ${ }^{[35]}$.

The design of the miniplates used in the current study was supposed to offer a vertical intrusive force as much as possible. According to several reports and clinical studies, an extra-alveolar buccal site for miniplate mounting was selected in the current study, which was the infrazygomatic crest (zygomatic buttress). This is considered as an optimal position for insertion because of being at a high vertical position that allowed for a wide range of activation for molar intrusion. In addition, being far away from the alveolar ridge and risks of injuring the teeth roots were minima ${ }^{[10,15,17,22,24,28]}$. Moreover, the current palatal mini-screws were placed directly apical to the first maxillary molar and at the junction between the vertical and the horizontal slopes of the palate without predrilling ${ }^{[12]}$. However, a previous systematic review claimed that cortical notching increased the success rate of the miniscrews as it provided a purchase point from which a more stable placement angle could be achieved ${ }^{[25]}$.

A high-mandibular plane angle was found to be a potential risk factor for the failure of screw-type anchors and the use of miniplates were suggested ${ }^{[36]}$. In a clinical study of adults with SAOB, Akay et al., used titanium screws of $2.3 \mathrm{~mm}$ diameter and 7, 9, $13 \mathrm{~mm}$ lengths and concluded that miniplates placed at zygomatic buttresses and buccal bone above the roots of premolars remained stable following application of intrusive forces ${ }^{[22]}$. In that study and other reports, no signs of mobility of titanium screws placed in the palatal bone were observed which was similar to the present findings ${ }^{[15,22,25]}$.

The intrusive force applied in this study was $150 \mathrm{gm}$ on each side, according to previous clinical reports ${ }^{[27,34]}$. Others suggested that, an initial force for molar intrusion was of $50 \mathrm{gm}$ for each molar ${ }^{[37]}$. However, an intrusive force of 200-300 gm for maxillary posterior teeth with 3 roots was also used ${ }^{[26,33]}$.

The results of this study revealed that both miniplates and palatal mini-screws can be successfully used for maxillary molar intrusion. These results agree with several studies which showed comparable amounts of successful molar intrusion using TADs ${ }^{[13,14,21]}$. On the other hand, other studies obtained different amounts of intrusion using TADs supported intrusive mechanics ${ }^{[15,33-35]}$. Sherwood et al., ${ }^{[15]}$ and Erverdi et al., ${ }^{[38]}$ used titanium miniplates at the lower face of the zygomatic process of maxilla to assist in the correction of SAOB. Sherwood et al., ${ }^{[15]}$ demonstrated a mean upper molar intrusion of $1.99 \mathrm{~mm}$ with intrusive forces continued for 5.5 months in 4 patients whereas Erverdi et al., ${ }^{[38]}$ reported a mean maxillary molar intrusion of $2.6 \mathrm{~mm}$ in 10 patients after a mean of 5.1 months. Interestingly, Yao et al. ${ }^{[39]}$ used a combination of buccal miniplates and palatal mini-screws in 18 patients and buccal and palatal mini-screws in 4 patients who had overerupted maxillary molars. They reported that the mean intrusion of maxillary first molars was 3 to $4 \mathrm{~mm}$ in a mean of 7.6 months.

Unfortunately, buccal tipping was unavoidable due to lack of the trans-palatal arch (TPA). In addition, the study design involved the application of palatal intrusive force via palatal mini-screws that made the use of TPA very difficult ${ }^{[12,39,40]}$. Sherwood et al., ${ }^{[15]}$ avoided the use of TPA to eliminate the added variable of intrusive forces from the tongue being applied to a TPA. However, several case reports have utilized TPA to counteract the buccal intrusive force $^{[21,24,27]}$.

The height of the crestal alveolar bone, measured in the current study, showed a significant decrease after intrusion. These findings could be attributed to the buccal tipping that was previously mentioned. The crestal alveolar bone height was rarely evaluated in previous studies concerning open bite correction. However, it was found to be decreased by $1.89(0.59) \mathrm{mm}$ after rapid maxillary expansion procedures ${ }^{[41]}$.

\section{CONCLUSION}

On the basis of the current results and with the limitations of the present study, the following conclusions could be drawn: 
1. The current miniplates' designs were effective for assistance of maxillary molar intrusion in cases of SAOB.

2. The posterior maxillary dento-alveolar heights as well as, the crestal alveolar bone heights diminished significantly.

3. The bucco-palatal angulations of maxillary first permanent molar crown revealed no major changes.

4. Virtual planning for the miniplates and 3D adaptation is highly recommended to provide accurate placement and to diminish the intraoperative time.

\section{CONFLICT OF INTEREST}

The authors declare no conflict of interest.

\section{REFERENCES}

1. Ross VA, Isaacson RJ, Germane N, and Rubenstein LK. Influence of vertical growth pattern on faciolingual inclination and treatment mechanics. Am J Orthod. 1990;98:422 - 9.

2. Sankey WL, Buschang PH, English J, and Owen AH. Early treatment of vertical skeletal dysplasia: the hyperdivergent phenotype. Am J Orthod Dentofacial Orthop. 2000;118:317 - 27.

3. Baccetti T, Franchi L, Schulz SO, and McNamara JA. Treatment timing for an orthopedic approach to patients with increased vertical dimension. Am J Orthod Dentofacial Orthop. 2008;133:58 - 64.

4. Firouz M, Zernik J, and Nanda R. Dental and orthopedic effects of high-pull headgear in treatment of Class II, division 1 malocclusion. Am J Orthod Dentofacial Orthop. 1992;102:197 - 205.

5. Deberardinis M, Stretesky T, Sinha P, and Nanda RS. Evaluation of the vertical holding appliance in treatment of high-angle patients. Am J Orthod Dentofacial Orthop. 2000;117:700 - 5.

6. Stuani MB and Stuani AS. Modified Thurow appliance: a clinical alternative for correcting skeletal open bite. Am J Orthod Dentofacial Orthop. 2005; 128:118 - 25.

7. Cozza P, Baccetti T, Franchi L, and Mucedero M. Comparison of 2 early treatment protocols for open-bite malocclusions. Am J Orthod Dentofacial Orthoped. 2007;132:743 - 7.
8. Defraia E, Marinelli A, Baroni G, Franchi L, and Baccetti T. Early orthodontic treatment of skeletal open-bite malocclusion with the openbite bionator: a cephalometric study. Am J Orthod Dentofacial Orthop. 2007;132:595 - 8.

9. Giuntini V, Franchi L, Baccetti T, Mucedero M, and Cozza P. Dentoskeletal changes associated with fixed and removable appliances with a crib in open-bite patients in the mixed dentition. Am J Orthod Dentofacial Orthop. 2008;133:77 - 80 .

10. Erverdi N, Usmez S, and Solak A. New generation open bite treatment with zygomatic anchorage. Angle Orthod. 2006;76:519 - 62.

11. Karthick D, Shetty, Vivek P, and Soni. Skeletal open bite: a non-surgical approach. A review of different techniques. Scientific J. 2007;1:72 - 9.

12. Park YC, Lee HA, Choi NC, and Kim DH. Open bite correction by intrusion of posterior teeth with mini-screws. Angle Orthod. 2008;67:699 - 710.

13. Mehmet CA, Aynur A, Tayfun G, Sercan A, and Banu OK. Enhanced effect of combined treatment with corticotomy and skeletal anchorage in open bite correction. J Oral Maxillofac Surg. 2009;67:563 - 9 .

14. Posterman B, Posterman L, Fisher R, and Gornitsky M. The use of implants for the orthodontic correction of an open bite. Am J Orthod Dentofacial Orthop. 1995;106:245 - 50.

15. Sherwood KH, Burch JG, and Thompson WJ. Closing anterior open bites by intruding molars with titanium miniplate anchorage. Am J Orthod Dentofacial Orthop. 2002;122:593 - 600.

16. Park HS, Kwon TG, and Kwon OW. Treatment of open bite with mini-screw implant anchorage. Am J Orthod Dentofacial Orthop. 2004;126:627 - 36.

17. Seres L, and Kocsis A. Closure of severe skeletal anterior open bite with zygomatic anchorage. J Craniofacial Surg. 2009;20:478 - 82.

18. Harta TR, Cousleyb RJ, Fishmanc LS, and Tallentsd RH. Dentoskeletal changes following mini-implant molar intrusion in anterior open bite patients. Angle Orthod. 2015;85:941 - 8 .

19. Hamdy MA. Effect of mini-screw implant supported intrusion on mandibular rotation in a group of children. Master thesis, Faculty of Oral and Dental Medicine, Cairo University, 2009. 
20. Deguchi T, Kurosaka H, Oikawa H, Kuroda S, TakahashiI, and Yamashiro T. Comparison of orthodontic treatment outcomes in adults with skeletal open bite between conventional edgewise treatment and implant-anchored orthodontics. Am J Orthod Dentofacial Orthop. 2011;139:60 - 8 .

21. Tuncer C, Atac MS, Tuncer BB, and Kaan E. Osteotomy assisted maxillary posterior impaction with miniplate anchorage. Angle Orthod. 2008;78:737 - 44 .

22. Akay MC. Corticotomy and miniplate anchorage for treating severe anterior open-bite: Current clinical applications. A textbook of advanced oral and maxillofacial surgery, InTech publisher, 2013;15:714 - 59 .

23. Leung MT, Lee TC, Rabie AB, and Wong RW. Use of Mini-screws and Miniplates in Orthodontics. J Oral Maxillofac Surg. 2008;66:1461 - 6.

24. Park JH, Tai K, and Takagi M. Open-bite treatment using maxillary and mandibular miniplates. J Clin Orthod. 2015:398 - 408.

25. Ng J, Major PW, and Flores-Mir C. True molar intrusion attained during orthodontic treatment: a systematic review. Am J Orthod Dentofacial Orthop. 2006;130:709 - 14

26. Park HS, Kwon OW, and Sung JH. Nonextraction treatment of an open bite with mini-screw implant anchorage. Am J Orthod Dentofacial Orthop. 2006;130:391 - 402.

27. Xun C, Zeng $X$, and Wang $X$. Microscrew anchorage in skeletal anterior open bite treatment. Angle Orthod. 2007;77:47 - 56.

28. Beycan K and Erverdi N. Anterior openbite treatment by means of zygomatic miniplates: a case report. J Istanbul Univ Fac Dent 2017;51:52 - 6 .

29. Cevidanes LHS, Styner MA, and Proffit WR. Image analysis and superimposition of 3-dimensional cone beam computed tomography models. Am J Orthod Dentofacial Orthop. 2006;129:611 - 8 .

30. Chen Y, Duan P, and Meng, Y. Three-dimensional spiral computed tomographic imaging: a new approach to the diagnosis and treatment planning of impacted teeth. Am J Orthod Dentofacial Orthop. 2006;130:112 - 6.

31. Deguchi T, Nasu M, Mukarami K, Yabuuchi $\mathrm{T}$, Kamioka $\mathrm{H}$, and Takano-Yamamoto $\mathrm{T}$.
Quantitative evaluation of cortical bone thickness with computed tomographic scanning for orthodontic implants. Am J Orthod Dentofacial Orthop. 2006;129:7 - 12 .

32. Hourfar J , Kanavakis G, Goellner P, Ludwig B.: Fully customized placement of orthodontic miniplates: a novel clinical technique. Head \& Face Med 2014;10:14.

33. Yu J-J, Kim G-T, Choi Y-S, Hwang E-H, Paek J, Kim S-H, Huang JC: Accuracy of a cone beam computed tomography-guided surgical stent for orthodontic mini-implant placement. Angle Orthod 2012;82:275 - 83.

34. Kim S-H, Choi Y-S, Hwang E-H, Chung K-R, Kook Y-A, Nelson G: Surgical positioning of orthodontic mini-implants with guides fabricated on models replicated with cone-beam computed tomography. Am J Orthod Dentofacial Orthop 2007;131:82-9.

35. Cornelis MA, Scheffler NR, Nyssen-Behets C, De Clerck HJ, Tulloch JFC: Patients' and orthodontists' perceptions of miniplates used for temporary skeletal anchorage: a prospective study. Am J Orthod Dentofacial Orthop 2008;133:18-24.

36. Lee JS, Kim DH, Park Y, Kyung S and Kim T. The efficient use of mid-palatal mini-screw implants. Angle Orthod. 2004;74:711 - 4.

37. Umemori M, Sugawara J, Mitani H, Nagasaka H and Kawamura H. Skeletal anchorage system for open-bite correction. Am J Orthod Dentofacial Orthop. 1999;115:166 - 74 .

38. Erverdi N, Keles A and Nanda R. The use of skeletal anchorage in open bite treatment: A cephalometric evaluation. Angle Orthod. 2004;74:381 - 90.

39. Yao CJ, Lee J, Chen H, Chang ZJ, Chang $\mathrm{H}$ and Chen $\mathrm{Y}$. Maxillary molar intrusion with fixed appliances and mini-implant anchorage studied in three dimensions. Angle Orthod. 2005;75:754 - 60 .

40. Wilmes B, Nienkemper M, Ludwig B, Nanda R and Drescher D. Upper-molar intrusion using anterior palatal anchorage and the mousetrap appliance. J Clin Orthod. 2013:315 - 20.

41. Brunetto M, Andriani J, Ribeiro G, Locks A, Correa $\mathrm{M}$ and Correab L. Three-dimensional assessment of buccal alveolar bone after rapid and slow maxillary expansion: A clinical trial study. Am J Orthod Dentofacial Orthop. 2013;143:633 - 44. 